\title{
COSTA RICA: UNA DECISIÓN ESTRATÉGICA EN TIEMPOS INCIERTOS
}

\author{
Costa Rica: An Strategic Decision in Uncertain Times
}

\author{
JORGE VARGAS CULLELL* \\ Programa Estado de la Nación
}

\begin{abstract}
RESUMEN
El 2007 estuvo marcado por el conflicto sobre la ratificación del Tratado de Libre Comercio entre Centroamérica, Estados Unidos y República Dominicana (CAFTA por sus siglas en inglés). El CAFTA fue aprobado por estrecho margen mediante referendum en octubre, luego de un período de polarización de las fuerzas políticas y sociales. El proceso reflejó la fragilidad del sistema de partidos políticos y las dificultades del gobierno y las fuerzas opositoras para lograr acuerdos políticos en otros ámbitos de la política pública.
\end{abstract}

Palabras clave: CAFTA, referendum, partidos políticos, comportamiento electoral, coaliciones parlamentarias, poderes de Estado, políticas públicas, Costa Rica.

\begin{abstract}
The conflict over the ratification of the Central American, United States and Dominican Republic Free Trade Agreement (CAFTA) dominated Costa Rican politics in 2007. CAFTA was approved by a narrow margin in a national referendum held in October, after a fractious and polarized campaign. The process reflected the transitional and fragile nature of the party system, and the difficulty to achieve consensus faced both by the government and the opposition.
\end{abstract}

Key words: CAFTA, referendum, political parties, electoral behavior, parliamentary coalitions, State Branches, public policies, Costa Rica.

\section{INTRODUCCIÓN}

El presente artículo analiza la situación política en Costa Rica durante el año 2007. El período bajo estudio comprende de enero a diciembre de ese año. Ahí donde es posible, los acontecimientos se analizan desde tres perspectivas: la valoración de su importancia política; su ubicación dentro de las tendencias más generales del desarrollo político e institucional reciente del país y, finalmente, su contraste con acontecimientos o tendencias en otros países de la región.

Las principales conclusiones son las siguientes: el año político estuvo dominado por el conflicto sobre la ratificación del Tratado de Libre Comercio entre Centroamérica, Estados Unidos y República Dominicana (en adelante CAFTA por sus siglas en inglés),

* El autor agradece a Noel Cuevas Vargas, quien recolectó la información de base para este artículo. Natalia Morales actualizó los indicadores del Cuadro 1. 
firmado por el Ejecutivo en febrero de 2004. Este es el primer conflicto importante en la era postbipartidista. ${ }^{1}$ Su resolución mediante referendum, celebrado en octubre, fue una opción resistida por el gobierno y los partidos políticos, aunque permitió resolver un tema empantanado en el Congreso pese a una mayoría parlamentaria de la coalición progubernamental de centroderecha. La polarización ideológica y política de fuerzas en relación con el CAFTA develó las dificultades del frágil sistema de partidos para lograr acuerdos políticos. El gobierno obtuvo buenos resultados económicos y sociales y logró la ratificación del CAFTA en las urnas; sin embargo, enfrenta severas dificultades para impulsar su agenda política y, en particular, aprobar rápidamente las leyes requeridas para la plena incorporación de Costa Rica a ese tratado. De toda suerte, por primera vez en la historia reciente el sistema político aprobó reformas institucionales tendientes al rompimiento de los monopolios públicos en la provisión de los servicios de telecomunicaciones y seguros. $\mathrm{Al}$ decir de un analista: “Por fin el país dobló la esquina” (Ulibarri 2008).

\section{HECHOS RELEVANTES Y SU SIGNIFICACIÓN POLÍTICA}

Por tercer año consecutivo, Costa Rica experimentó un rápido crecimiento económico. En el 2007 el PIB per cápita creció un 4,5\%, muy por encima del promedio 2001-2006 y, además, por encima del promedio de América Latina en este año. ${ }^{2}$ El PIB per cápita es aproximadamente un $40 \%$ más alto que el del inicio de la década (US\$ 5.766 frente a US\$ 4.092 en el 2000). Se estima que las exportaciones rondarán los US\$ 9.200 millones al finalizar el 2007, un crecimiento cercano al 15\%; y que la inversión extranjera directa sea similar al máximo histórico del año 2006. El único resultado negativo fue la incapacidad para lograr la meta inflacionaria $(8 \%)$, pese a la capitalización del Banco Central (la inflación será cercana al 10\%). En resumen, desde el punto de vista económico, Costa Rica fue parte de la tendencia de la mayoría de los países latinoamericanos a experimentar un rápido crecimiento económico que, de acuerdo con CEPAL, forma parte de la fase más prolongada y favorable que ha vivido la región desde los años sesenta (CEPAL, 2007).

Desde el punto de vista social, el año 2007 arrojó buenos resultados, aunque menos robustos. Por primera vez en más de una década, la incidencia de la pobreza disminuyó de manera significativa ( $-3,5$ puntos porcentuales) debido a factores reales y no metodológicos, por lo que ésta pasó a afectar del 20,1\% al 16,7\% de los hogares. La baja fue provocada por el crecimiento en el ingreso de los ocupados y el aumento de las pensiones de la seguridad social (Sauma, 2007). El desempleo abierto y el subempleo también disminuyeron de manera apreciable (Cuadro 1). Sin embargo, es importante anotar que la desigualdad

1 En la segunda mitad del siglo XX el sistema de partidos era bipolar: el Partido Liberación Nacional (PLN) era la fuerza dominante y el antiliberacionismo, la reactiva. El antiliberacionismo estaba conformado por un heterogéneo y cambiante grupo de partidos. No fue sino hasta 1982, cuando el antiliberacionismo conformó al Partido Unidad Social Cristiana (PUSC), que el sistema de partidos adoptó un formato bipartidista. El binomio PLN - PUSC dominó la política costarricense entre 1982 y 2002.

2 De acuerdo con CEPAL, el PIB per cápita en Costa Rica creció 5,2\% en 2007, mientras que el promedio latinoamericano fue 4,2\%. Esta estimación es discrepante con la reportada por el Banco Central, que es la que se emplea en el texto y en el Cuadro 1 para mantener la consistencia de la serie temporal. 
social volvió a incrementarse, aunque levemente. Así, el promedio del coeficiente de Gini en el período 2003-2007 es cinco puntos mayor al promedio observado a mediados de la década anterior. Debe recordarse, finalmente, que los buenos resultados reseñados en pobreza, empleos e ingresos son los primeros efectos positivos luego de varios años de rápido crecimiento, lo que sugiere débiles encadenamientos entre el comportamiento de las variables económicas y las sociales.

Cuadro 1: Costa Rica: indicadores seleccionados de su evolución económica y social 2001-2007

\begin{tabular}{lrrrrrrrr}
\hline \multicolumn{1}{c}{ Indicador } & 2001 & 2002 & 2003 & 2004 & 2005 & 2006 & $\begin{array}{r}\text { Promedio } \\
2001-2006\end{array}$ & $2007^{\mathrm{a}}$ \\
\hline Crecimiento poblacional & 2,1 & 2,0 & 1,9 & 1,9 & 1,8 & 1,7 & 1,9 & 1,7 \\
Crecimiento PIB por habitante & $-1,0$ & 0,9 & 4,4 & 2,4 & 4,0 & 6,3 & 2,8 & 5,2 \\
PIB (per cápita US\$ corrientes) & 4.092 & 4.119 & 4.200 & 4.376 & 4.616 & 5.051 & 4.409 & 5.766 \\
Exportaciones (millones de dólares) & 5.021 & 5.264 & 6.102 & 6.302 & 7.026 & 8.200 & 6.319 & $7.841^{* *}$ \\
Déficit Cuenta Corriente (\% del PIB) & 3,7 & 5,1 & 5,0 & 4,3 & 4,9 & 5,0 & 4,7 & \\
IED* (millones de dólares) & 460 & 659 & 575 & 794 & 861 & 1.469 & 803 & \\
IED (\% del PIB) & 2,8 & 3,9 & 3,3 & 4,3 & 4,3 & 6,6 & 4,2 & \\
Inflación (Cambio anual IPC***) & 11,0 & 9,7 & 9,9 & 13,1 & 14,1 & 9,4 & 11,2 & 10,2 \\
Tasa de desempleo abierto & 6,1 & 6,4 & 6,7 & 6,5 & 6,6 & 6 & 6,4 & 4,6 \\
Tasa de subempleo total & 7,3 & 8,2 & 8,3 & 7,9 & 8,4 & 9 & 8,2 & 7,4 \\
Hogares pobres (porcentaje) & 20,3 & 20,6 & 18,5 & 21,7 & 21,2 & 20,2 & 20,4 & 16,7 \\
Coeficiente de Gini & 43,3 & 43,0 & 42,5 & 41,8 & 40,6 & 42,0 & 42,2 & 42,7 \\
Índice de gasto público social real & 104,1 & 104,8 & 107,3 & 105,1 & 102,7 & 107,2 & 105,2 & \\
per cápita (2000 = 100) & & & & & & & & \\
\hline
\end{tabular}

Fuente: Programa Estado de la Nación con base en Banco Central, Instituto Nacional de Estadística y Censos.

* Inversión extranjera directa.

** A octubre 2007.

*** Índice de precios del consumidor.

a cifras preliminares sujetas a modificación.

Los buenos resultados económicos y sociales permitieron al gobierno mantener una valoración ciudadana favorable a su gestión, situación contrastante con la experiencia de las dos administraciones anteriores, que sufrieron una rápida erosión de su capital político en el segundo año de labores. El nivel de aprobación presidencial se estuvo estable por encima del $55 \%$ a lo largo del año, un umbral favorable en el contexto latinoamericano. ${ }^{3}$

3 El seguimiento periódico de Consulta Mitofski, con fuente CID-GALLUP señala que en noviembre 2006 el presidente contaba con una aprobación del 56\%; en marzo de $2007,55 \%$ y en octubre del $60 \%$. En ese mes, era el cuarto mandatario mejor calificado en América Latina. 
Los favorables resultados en la opinión pública fortalecieron la capacidad gubernamental para mantener unida a una heterogénea coalición parlamentaria ${ }^{4}$ durante el conflicto por el CAFTA y su resolución mediante el referendum celebrado en octubre del 2007. Tomando en cuenta la experiencia internacional en materia de referendums de alcance nacional (Kowalska et al., 2005; Leduc, 2002; Maravall, 2003; Mendelsohn et al, 2001), una mayoritaria percepción favorable al gobierno fue un factor que no introdujo vulnerabilidades adicionales a la campaña gubernamental a favor de su ratificación. Sin embargo, los buenos resultados no se tradujeron en un capital político que le permitiera tomar la iniciativa política e impulsar sus prioridades de política pública en otros ámbitos. Por el contrario, la acción gubernamental enfrentó profundas resistencias y los partidos de oposición han frenado por largo tiempo su agenda parlamentaria. Aún hoy, pese al resultado favorable a la ratificación del CAFTA, el gobierno tiene un escaso y conflictivo margen de maniobra.

\section{CAMBIOS CONSTITUCIONALES, INSTITUCIONALES Y EN POLÍTICAS PÚBLICAS}

En el 2007 no se registraron reformas constitucionales (véase sección 8) ni se implementaron reformas institucionales. El Parlamento no aprobó piezas de legislación que implicaran cambios en las políticas públicas, excepto en lo referente a la violencia doméstica y la tutela de derechos de menores de edad (véase sección 6). En términos de políticas públicas, lo más relevante del año fue, en primer lugar, la presentación del Plan Nacional de Desarrollo 2007-2011 “Jorge Manuel Dengo", en enero de 2007 (MIDEPLAN, 2007) y, en segundo lugar, el aumento en la recaudación tributaria y la puesta en marcha de nuevas políticas sociales.

El Plan Nacional de Desarrollo distingue tres tipos de medidas: las que el Ejecutivo puede realizar sin necesidad de cambios legislativos ("contrato con la ciudadanía"), 5 las propuestas de política que requieren aprobación legislativa ("compromiso con la ciudadanía"); y los temas de reforma política y económica sobre los cuales el Ejecutivo se comprometió a convocar diálogos sociales ("Diálogos del Bicentenario"). En relación con el "contrato con la ciudadanía", las medidas más relevantes fueron la ampliación del programa "Avancemos" -transferencias monetarias condicionadas a hogares que mantengan a sus hijos estudiando en el sistema educativo-, el aumento de las pensiones no contributivas de la seguridad social para las personas de más bajos ingresos, el programa nacional de erradicación de tugurios para eliminar cerca del 50\% de las habitaciones en precario y el aumento del esfuerzo de recaudación tributaria. Todas estas políticas fueron aplicadas durante el 2007 con resultados tangibles excepto en lo concerniente al programa de erradicación de precarios, que no ha podido arrancar.

\footnotetext{
Esta coalición de cinco partidos controla dos terceras partes de los escaños.

Estas medidas se aplicarían mediante la publicación de Decretos Ejecutivos, una facultad de legislación ordinaria del Ejecutivo costarricense. Debe indicarse que dicha facultad está subordinada a la legislación ordinaria que apruebe el Parlamento, por ser de menor rango legal de acuerdo con la Constitución Política. Las facultades del Ejecutivo de legislar vía decretos de emergencia nacional es muy restringida.
} 
En relación con los "compromisos con la ciudadanía" las medidas más significativas preconizadas por el Plan fueron una reforma fiscal, la transformación de las instituciones de fomento a la producción agropecuaria e industrial y la consecuente creación del Ministerio de la Producción y, además, el establecimiento del Ministerio de Desarrollo Social. Ninguna de estas propuestas fue presentada a la consideración del Parlamento. En relación con los "Diálogos del Bicentenario" ninguno fue convocado, pues por las razones que se explican en la siguiente sección no hubo condiciones políticas apropiadas.

\section{POLÍTICA ELECTORAL: EL REFERENDUM SOBRE LA RATIFICACIÓN DEL CAFTA}

La celebración de un referendum para decidir sobre la ratificación del CAFTA fue el principal, e inesperado, acontecimiento político del año. A inicios del 2007 tanto el gobierno como los principales partidos de oposición habían coincidido en librar en el Congreso la batalla de la ratificación. En particular, el presidente se oponía al empleo de una consulta ciudadana vinculante como el referendum. ${ }^{6}$ Por su parte, la mayoría de las organizaciones sociales y laborales contrarias al CAFTA impulsaban las movilizaciones populares masivas como estrategia para derrotar al gobierno y su coalición parlamentaria. Así, en octubre de 2006 y en febrero de 2007 se realizaron manifestaciones multitudinarias en contra del CAFTA. En este contexto, el ex candidato presidencial del PLN, José Miguel Corrales, opositor al CAFTA, planteó ante el Tribunal Supremo de Elecciones (TSE) la propuesta de realizar un referendum para dirimir la ratificación del CAFTA utilizando la opción de la iniciativa ciudadana contemplada en la Ley 8492 que regula esta materia. ${ }^{7}$

El 12 de abril del 2007, el TSE aceptó la excitativa de Corrales y le autorizó iniciar la recolección de firmas (Resolución 790-E-2007). Esta sentencia precipitó un giro en el conflicto y el consecuente abandono de la vía parlamentaria para la ratificación del CAFTA. Como la iniciativa ciudadana implica un proceso no menor a 15 meses entre la recolección de firmas, verificación, convocatoria y realización de la consulta, el referendum se realizaría fuera del plazo que el país tenía para ratificar el tratado según el texto del CAFTA (vence el 29 de febrero de 2008). Si los proponentes del referendum lograban colectar las firmas necesarias, en la práctica Costa Rica quedaba fuera del CAFTA pues, una vez convocada la consulta, el Parlamento debía suspender el proceso de aprobación del tratado y esperar la decisión popular al respecto. Enfrentado al empantanamiento legislativo de la ratificación (véase sección 6), y ante el peligro de que la iniciativa ciudadana prosperara, el gobierno no tuvo otra opción que modificar su posición. Envió al Congreso una solicitud para convocar al referendum que fue rápidamente aprobada por éste. Como el Ejecutivo completó los

\footnotetext{
En el referendum la ciudadanía se convierte en el legislador.

La ley contempla tres vías para la convocatoria al referendum: la iniciativa ciudadana, que requiere del $5 \%$ de las firmas del electorado para proceder a la convocatoria; la iniciativa del congreso, que requiere la aprobación de una mayoría parlamentaria calificada (dos terceras partes); y la iniciativa del Ejecutivo, que requiere aprobación legislativa por mayoría simple. En el caso de la iniciativa ciudadana el TSE debe verificar, previo al inicio de la recolección de firmas, que el tema en cuestión se ajuste a los asuntos que, de acuerdo con la ley, no están excluidos expresamente de la aplicación de este mecanismo (por ejemplo, la materia fiscal entre otras).
} 
requisitos antes de los propulsores del referendum vía iniciativa ciudadana, el TSE dio curso al evento. Luego de consultas ante la Sala Constitucional, y ante la protesta de Corrales, el tribunal fijó la fecha del referendum para el día 7 de octubre de 2007.

Por una mayoría muy ajustada, y luego de una virulenta y polarizada campaña electoral, la ciudadanía aprobó la ratificación del CAFTA $51 \%$ a $48 \%$. La participación fue relativamente alta $(60 \%)$, tomando en cuenta que el voto no es obligatorio ${ }^{8}$ y la complejidad del objeto de la decisión -un tratado multilateral de libre comercio. Tanto las fuerzas del SÍ como las del NO fueron muy heterogéneas y es preciso subrayar que los principales protagonistas en la campaña electoral no fueron los líderes partidarios sino el gobierno por el lado del SÍ, y un conjunto de intelectuales y líderes sociales por parte el NO.

Ambas partes crearon estructuras políticas y organizativas independientes de los partidos para dirigir las respectivas campañas electorales. En especial, cabe anotar el surgimiento de los Comités Patrióticos en el bando del NO, una vasta red de organizaciones locales que se declara independiente de cualquier partido. El SÍ contó con una evidente ventaja en materia de financiamiento político, lo que le permitió un gasto en publicidad en los medios de comunicación ocho veces superior en relación al gasto del NO: US\$1,75 millones a US\$ 0,21 millones (Semanario Universidad, 2007).

Frente a un electorado con importantes dudas y niveles de indecisión, las fuerzas del Sí y del NO acudieron a distintos argumentos políticos, ideológicos y legales. En términos generales, el SÍ presentó al CAFTA como la piedra angular del desarrollo futuro del país y la reafirmación del estilo de desarrollo adoptado desde los años ochenta. Además, advirtieron sobre el peligro que significaba quedarse aislado del resto de la región, pues los demás países centroamericanos ya habían ratificado el tratado, y en especial, del peligro que significaba el rechazo del CAFTA para las relaciones con el principal socio comercial del país. Además, utilizaron el expediente anticomunista para difundir la idea de que Fidel Castro y Hugo Chávez (presidentes cubano y venezolano respectivamente) estaban promoviendo a los opositores. Por su parte el NO acusó al CAFTA de ser la pieza que liquidaría el Estado social de derecho costarricense, por promover la apertura (privatización disfrazada) de los sectores de telecomunicaciones, seguros y la seguridad social. Caracterizó al CAFTA como una imposición norteamericana, con la complicidad de élites político-económicas locales, para quedarse con los activos del pueblo costarricense. Señaló que el tratado había sido mal negociado, especialmente lo referente a la propiedad intelectual, donde se acusó a los negociadores de haber cedido a las presiones de los grandes farmacéuticos. Finalmente, llamó a derrotar al modelo neoliberal mediante el voto en las urnas.

Ambas partes desarrollaron campañas "negras", con distinta intensidad y por medios diversos. En los últimos dos meses de proceso, el gobierno estuvo acosado debido al escándalo provocado por la filtración de un memorandum recomendando el miedo y la política dura como tácticas, escrito por el segundo vicepresidente y un diputado oficialista

8 El artículo 93 de la Constitución Política define al voto como una "función cívica primordial y obligatoria" pero no establece ninguna sanción. En consecuencia, abstenerse a votar en cualquier elección que se celebre en Costa Rica no es sancionado por la ley. 
(el memo Sánchez-Casas). Los sondeos de opinión pública realizados en el último mes reflejaron un fuerte descenso del SÍ como consecuencia del escándalo, en el contexto de importantes fluctuaciones en la intención de voto de amplios segmentos del electorado.

Visto en una perspectiva puramente electoral, los partidos que apoyaron públicamente el SÍ (el PLN y la coalición de centro-derecha) vieron disminuir su apelación al electorado en relación con los votos obtenidos en las elecciones nacionales presidenciales y legislativas de febrero 2006; por su parte, los partidos que apoyaron públicamente al NO lograron importantes avances. Aunque insuficiente para ganar, el NO atrajo los votos de electores que en las elecciones nacionales apoyaron a partidos que no se pronunciaron a favor o en contra del CAFTA (Cuadro 2). Es difícil saber si estos resultados influirán de alguna manera en el proceso electoral de 2009-2010.

Cuadro 2: Costa Rica: datos básicos sobre el referendum sobre el TLC de octubre 2007 y las elecciones nacionales de 2006

\begin{tabular}{|c|c|c|c|c|}
\hline Asunto & $\begin{array}{c}\text { Referendum } \\
\text { TLC } \\
\text { (Oct 2007) }\end{array}$ & $\begin{array}{c}\text { Elecciones } \\
\text { Presidenciales } \\
\text { (Feb 2006) }\end{array}$ & $\begin{array}{l}\text { Elecciones } \\
\text { Legislativas } \\
\text { (Feb 2006) }\end{array}$ & $\begin{array}{c}\text { Cambio } \\
2006-2007\end{array}$ \\
\hline Juntas Receptoras de Votos & 4.932 & 6.163 & 6.163 & -1.231 \\
\hline Padrón electoral & 2.654 .493 & 2.550 .607 & 2.550 .607 & 103.886 \\
\hline Votos válidos & 1.572 .603 & 1.663 .224 & 1.628 .824 & -90.621 \\
\hline Nivel de abstención (\%) & 40,8 & 34,8 & 36,1 & 6,0 \\
\hline \% votación obtenida por el Sí & 51,2 & 54,7 & 54,9 & $\begin{array}{l}-3,5 \% \text { presidencial } \\
-3,7 \% \text { legislativo }\end{array}$ \\
\hline \% votación obtenida por el NO & 48,1 & 39,9 & 27,9 & $\begin{array}{l}8,2 \% \text { presidencial } \\
20,2 \% \text { legislativo }\end{array}$ \\
\hline$\%$ votos no adjudicables & 0,6 & 5,3 & 34,8 & $-4,7$ \\
\hline
\end{tabular}

Notas: El Sí fue apoyado por los siguientes partidos: Partido Liberación Nacional (PLN -gobierno), Partido Unidad Socialcristiana (PUSC), Movimiento Libertario (ML), Partido Restauración Nacional (PRN), Partido Unión Nacional (PUN). El No fue apoyado por los siguientes partidos: Partido Acción Ciudadana (PAC), Frente Amplio (FA), Partido Accesibilidad Sin Exclusión (PASE). Los votos no adjudicables incluyen: votos blancos, nulos y de los partidos que no efectuaron manifestación pública en relación con el CAFTA.

Fuente: elaboración propia con base en los resultados definitivos del escrutinio de las elecciones presidenciales y legislativas de febrero $2006 \mathrm{y}$ del referendum sobre el CAFTA emitido por el Tribunal Supremo de Elecciones (TSE), www.tse.go.cr

\section{Limpieza del proceso electoral}

En contraste con las elecciones nacionales de febrero de 2006 (Alfaro 2007), los ajustados resultados en el referendum no desataron amplios cuestionamientos sobre la limpieza del proceso electoral en los medios de comunicación y ante el TSE. Pocas horas después de conocerse estos resultados los principales dirigentes del NO reconocieron la derrota, aunque señalaron hechos que a su juicio habrían comprometido la equidad y transparencia 
del proceso. En total, el PAC presentó denuncias por irregularidades en aproximadamente el 2,5\% de los centros de votación (Cuadro 3). Las denuncias alegaron que la ausencia parcial de material electoral impedía tener certeza sobre los resultados reportados en estas mesas. Los alegatos fueron rechazados por el TSE pero aun cuando los hubiese aceptado no habrían variado los resultados de la consulta.

En círculos políticos e intelectuales reducidos se sostiene la tesis de que el proceso electoral en su conjunto fue fraudulento. El ex candidato presidencial del PLN José Miguel Corrales y otros presentaron una denuncia contra la legalidad del proceso aduciendo que errores en el objeto de la convocatoria así como las actuaciones del gobierno y una alegada parcialidad del TSE eran causales para decretar la nulidad de la consulta. La denuncia fue rechazada por el TSE. En términos de la opinión pública, y pese a las constantes acusaciones de parcialidad contra el tribunal por algunos sectores del $\mathrm{NO}$ a lo largo de todo el proceso, más del $70 \%$ de la población consideró que el TSE organizó bien los comicios, fue imparcial y aceptó como legítimos los resultados de la consulta (CID, 2007).

Cuadro 3: Costa Rica: denuncias contra la legalidad y limpieza de los resultados del referendum sobre el CAFTA de Octubre 2007

\begin{tabular}{|c|c|c|c|c|c|}
\hline $\begin{array}{c}\text { Tipo de } \\
\text { denuncia }\end{array}$ & Fecha & $\begin{array}{c}\text { JRV } \\
\text { impugnadas }\end{array}$ & $\begin{array}{l}\% \text { de total } \\
\text { JRV (4932) }\end{array}$ & Alegación & $\begin{array}{c}\text { Resolución } \\
\text { TSE }\end{array}$ \\
\hline \multicolumn{6}{|c|}{ Específicas (contra resultados reportados por centros de votación) } \\
\hline No 2935-E-2007 & $19 / 10 / 2007$ & 53 & 1,1 & $\begin{array}{l}\text { Ausencia parcial } \\
\text { de material electoral }\end{array}$ & $\begin{array}{l}\text { Rechazada } \\
\text { por fondo }\end{array}$ \\
\hline $\mathrm{N}^{\mathrm{o}} 2939-\mathrm{E}-2007$ & $22 / 10 / 2007$ & 8 & 0,2 & $\begin{array}{l}\text { Ausencia parcial } \\
\text { de material electoral }\end{array}$ & $\begin{array}{l}\text { Rechazada } \\
\text { por fondo }\end{array}$ \\
\hline $\mathrm{N}^{\mathrm{o}} 2934-\mathrm{E}-2007$ & $19 / 10 / 2007$ & 62 & 1,3 & $\begin{array}{l}\text { Ausencia parcial } \\
\text { de material electoral }\end{array}$ & $\begin{array}{l}\text { Rechazada } \\
\text { por fondo }\end{array}$ \\
\hline N. ${ }^{\text {o } 2919-E-2007 ~}$ & $19 / 10 / 2007$ & 1 & 0,0 & $\begin{array}{l}\text { Ausencia parcial } \\
\text { de material electoral }\end{array}$ & $\begin{array}{l}\text { Rechazada } \\
\text { por fondo }\end{array}$ \\
\hline \multicolumn{6}{|c|}{ Generales (contra la legalidad del proceso de referendum) } \\
\hline $\mathrm{N}^{\mathrm{o}} 2941-\mathrm{E}-2007$ & $22 / 10 / 2007$ & & & Proceso fraudulento & $\begin{array}{l}\text { Rechazada } \\
\text { por forma }\end{array}$ \\
\hline
\end{tabular}

Fuente: Elaboración propia con base en las resoluciones indicadas en el cuadro.

Notas: Las denuncias clasificadas como "específicas" fueron presentadas por el fiscal del PAC. La denuncia clasificada como general fue presentada por un grupo de ciudadanos.

JRV: junta receptora de votos.

Ausencia parcial de material electoral: se alega que la ausencia de uno o más de los documentos que forman parte del material electoral impide tener certeza sobre los votos escrutados en la JRV.

Proceso fraudulento: Violación de la tregua y beligerancia política del Ejecutivo, intromisión de gobierno EEUU, inequidad de recursos y subordinación del TSE al gobierno.

Rechazo por el fondo: se admite la denuncia para su consideración pero se la descarta debido a razones sustantivas.

Rechazo por forma: se declara improcedente por no ajustarse a los términos y requisitos exigidos por el TSE. 


\section{Análisis de resultados}

En todos los municipios del país la apelación electoral del NO al CAFTA creció en relación con la obtenida en los comicios nacionales del 2006 (por los partidos que se identificaron con esa causa) aunque, como se indicó, esta ganancia fue insuficiente para obtener el triunfo en el referendum..$^{9}$ En promedio, el $\mathrm{NO}$ aumentó su arrastre en 22 puntos porcentuales. Salvo en pocos municipios, las fuerzas del Sí, victoriosas en el referendum, experimentaron importantes retrocesos. ${ }^{10}$

Existe una relación inversa entre el abstencionismo y los resultados electorales en el 2007 (Gráfico 1). En los municipios, donde el aumento de la abstención fue más bajo, las fuerzas favorables al NO registraron sus menores ganancias. ${ }^{11}$ En estos sitios las fuerzas del SÍ obtuvieron pequeñas pérdidas y hasta algunas ganancias. En cambio, en los cantones donde hubo un fuerte incremento del abstencionismo, el NO registró ganancias iguales o superiores a 20 puntos porcentuales entre el 2006 y el 2007 y el Sí pérdidas iguales o superiores a 10 puntos porcentuales.

Un examen más detenido de los resultados electorales del 2006 y $2007^{12}$ revela un cuadro más complejo. El factor predictivo más importante del cambio político es el nivel de desarrollo humano del municipio (Cuadro 4). En el análisis de regresión simple efectuado, ${ }^{13}$ el Coeficiente B estandarizado de este factor es, por mucho, el más alto de las variables consideradas. Entre mayor sea el desarrollo humano, menor es la ganancia del NO y más pequeña la pérdida del Sí. Por su parte, el tamaño poblacional del municipio y, como ya se vio, el cambio en el abstencionismo son también factores relevantes, aunque de menor importancia. En términos generales, entre más pequeña es la población del municipio, mayor es el avance de las fuerzas del NO; entre más grande la población, menor es su

9 En el análisis de los cambios en el arrastre electoral entre el referendum sobre el CAFTA y los comicios nacionales de febrero de 2006, se utilizará las elecciones legislativas como referencia. En éstas el PAC, principal partido opositor, obtuvo un $26 \%$ del voto, en comparación con el $39 \%$ logrado en las presidenciales. El caudal electoral del PAC en las elecciones legislativas es probablemente una mejor medida de su tamaño, pues una buena parte de los electores que votaron por su candidato presidencial eran simpatizantes del PUSC desencantados con su partido (UNIMER 2005, 2006). Aún así, las conclusiones del análisis de esta sección se mantienen si se realiza a partir de los comicios presidenciales.

10 La correlación entre ganancias de uno y pérdidas de otros es casi perfecta (-.99) tanto si considera el cambio en el arrastre electoral en relación con las elecciones presidenciales como con las legislativas del 2006. Los partidos neutrales (no manifestaron posición sobre el CAFTA) obtuvieron una votación muy baja en el 2006. Por la colinearidad entre ganancias de uno y pérdidas de otro, en lo que sigue se utiliza el cambio en el arrastre electoral del NO como medida resumen de ambos resultados electorales.

11 En esas zonas las ganancias fueron siempre importantes, del orden de 10 puntos porcentuales.

12 Para la determinación de las ganancias (o pérdidas) electorales se procedió de la siguiente manera: (a) identificación de la postura pública de los partidos en relación con la ratificación delCAFTA; (b) determinación de los votos obtenidos por estos partidos en las elecciones nacionales de 2006, presidenciales y legislativas; (c) sumatoria de los votos de todos los partidos coaligados a favor del SÍ y a favor del NO en las elecciones de 2006; (d) comparación de los resultados globales de 2006 con los obtenidos por el Sí y por el NO en el referendum.

13 La variable dependiente (Cambio en el arrastre electoral del NO) tiene una distribución normal, y las pruebas efectuadas muestran que se cumplen con los supuestos de linealidad, independencia, homocedasticidad y no-colinealidad. Para cumplir estos requisitos fue necesario eliminar del análisis un caso extremo, el Cantón de San Ramón en la Provincia de Alajuela, que tuvo un comportamiento atípico. Este es un municipio con un alto nivel de desarrollo humano, bajo nivel de urbanización y tamaño poblacional donde el NO obtuvo ganancias inordinales (44 puntos porcentuales). 
Gráfico 1: Costa Rica: Ganancias y pérdidas de las fuerzas a favor del Sí y del NO en el referendum sobre el CAFTA de octubre 2007 en relación con las elecciones nacionales de febrero 2006, según el cambio en el nivel de abstencionismo por municipio

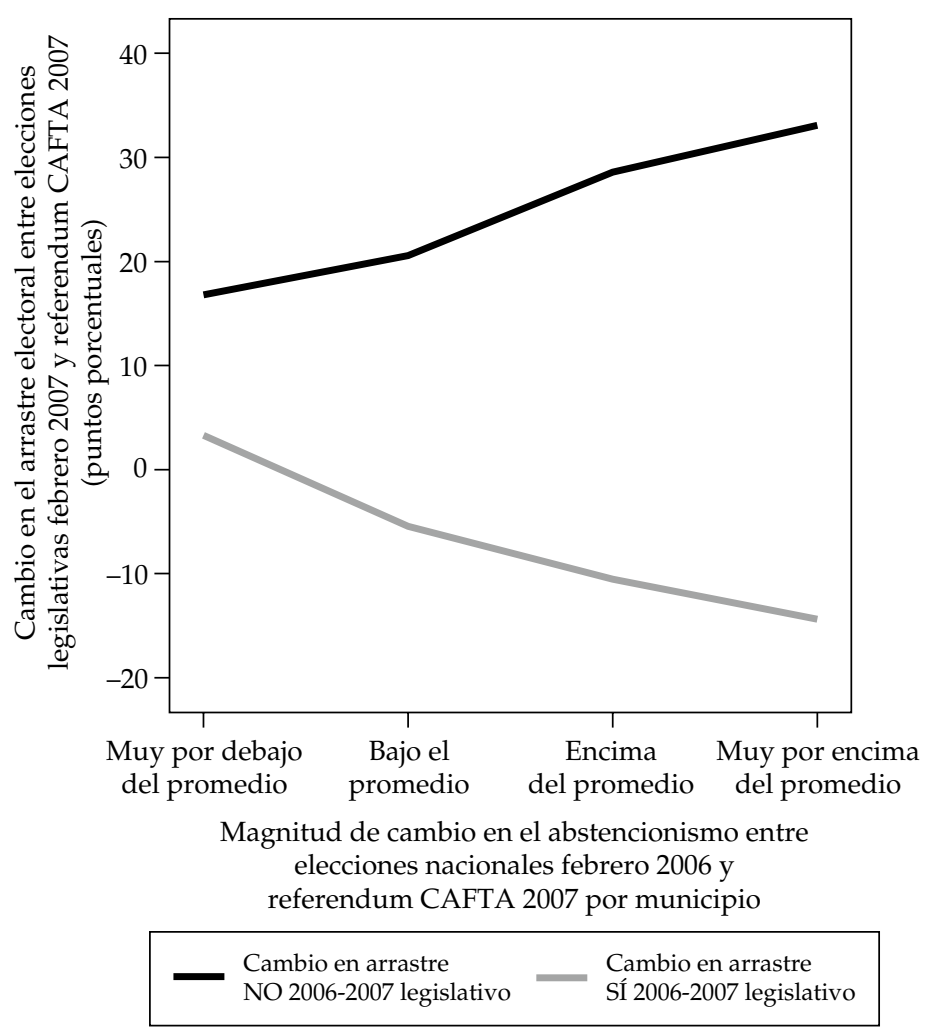

Fuente: Elaboración propia con base en el escrutinio definitivo del TSE sobre los resultados del referendum de octubre 2007 y de las elecciones nacionales de febrero de 2006. En: www.tse.go.cr Nota: El promedio del cambio en el abstencionismo por municipio es 7,16 puntos porcentuales. Los niveles están definidos a partir de desviaciones estándares $(3,40)$. Muy por encima (o por debajo) del promedio: una o más desviaciones estándares hacia abajo (arriba) del promedio.

El aumento promedio del abstencionismo por municipio $(7,16)$ no coincide con el aumento promedio nacional $(6,0)$, por calcularse a partir de los 81 cantones por separado.

ganancia. Por la colinearidad entre población y urbanización, ello significa que el NO obtuvo sus mayores avances en los municipios rurales y sus menores en los municipios urbanos. ${ }^{14}$ La relación entre los cambios en el abstencionismo y los resultados electorales, ya descrita en párrafos anteriores, se mantuvo al ser controlada por otros factores.

14 La población del municipio está altamente correlacionada $(R=.901)$ con el nivel de urbanización, según los datos del Censo de Población del 2000. 
Cuadro 4: Correlatos del cambio en el arrastre electoral de las fuerzas a favor del NO al CAFTA entre las elecciones legislativas de 2006 y el referendum del 2007

\begin{tabular}{lccc}
\hline \multicolumn{1}{c}{ a } & B & Std. B & Sig \\
\hline Constante & 67,63 & * $^{* * *}$ \\
Cambio abstencionismo 2006-2007 & $(13,05)$ & \\
& 0,84 & $0,29^{* *}$ \\
Índice de desarrollo humano 2005 & $(0,30)$ & \\
& $-0,66$ & $-0,43^{* * *}$ \\
Tamaño demográfico relativo del cantón ${ }^{\mathrm{b}}$ & $(0,16)$ & $-0,15^{*}$ \\
& $-0,09$ & \\
\hline
\end{tabular}

${ }^{*}$ Sig $<.1$.

** Sig $<.01$.

*** Sig $<0.001$.

a Variable Dependiente: Cambio en arrastre NO entre elección legislativa 2006 y referendum CAFTA 2007.

b Tamaño demográfico relativo: población del cantón Xj/población del cantón más poblado del país.

Cuando se examinan los resultados electorales a partir de la consideración conjunta del desarrollo humano local y el abstencionismo aparecen importantes especificaciones. En primer lugar, todos los cantones con un bajo incremento de abstencionismo poseen un nivel de desarrollo humano local superior al promedio nacional; en ellos, las ganancias del NO son menores y decrecientes conforme aumenta este desarrollo. Los centros urbanos fueron los que más se implicaron en la batalla por el referendum. En segundo lugar y de manera similar, hay una relación inversa entre las ganancias electorales del $\mathrm{NO}$ y el desarrollo humano si el aumento del abstencionismo estuvo cercano al promedio o por debajo de éste. Finalmente, las ganancias electorales del NO entre el 2006 y el 2007 son altas e independientes del nivel de desarrollo humano local si el aumento en la abstención fue muy alto (Gráfico 2).

La interpretación de estos resultados es la siguiente: el NO obtuvo sus más grandes éxitos en las zonas de menor desarrollo humano, más rurales y donde hubo mayor aumento del abstencionismo. Estas zonas han sido tradicionalmente baluartes de los partidos tradicionales (PLN-PUSC). Esto sugiere que una parte del electorado más tradicional se abstuvo de participar en el referendum, situación que estuvo a punto de costarle la victoria al Sí. Empero, los problemas de convocatoria del Sí se extendieron a otras zonas. Ahí donde la abstención experimentó un salto, el SÍ recogió fuertes retrocesos incluyendo a algunos municipios de alto desarrollo humano, de carácter más urbano.

Los resultados del referendum de octubre de 2007 sugieren, nuevamente, la existencia de una fluida situación política que, como ocurrió en eventos electorales anteriores (2002 y 2006), desemboca cerrado equilibrio de fuerzas. Hoy en día este equilibrio está encabezado, desde el punto de vista electoral, por el PLN y el PAC. Cada uno enfrenta 
desafíos específicos que, vistos en conjunto, provocan una importante incertidumbre política. Por el lado del gobierno (PLN), si bien logró triunfar en el referendum, lo hizo muy ajustadamente y con el concurso de varios partidos con los cuales se enfrentará en las elecciones del 2010. Por su parte, el PAC tiene el importante reto de retener el amplio apoyo que desde el 2002 logra en todo proceso electoral en el que participa. ${ }^{15}$

Gráfico 2: Costa Rica: Cambio en el arrastre electoral de las fuerzas de NO en el referendum sobre el CAFTA de octubre 2007 en relación con las elecciones nacionales de febrero 2006 según nivel de desarrollo local y magnitud del cambio en el abstencionismo

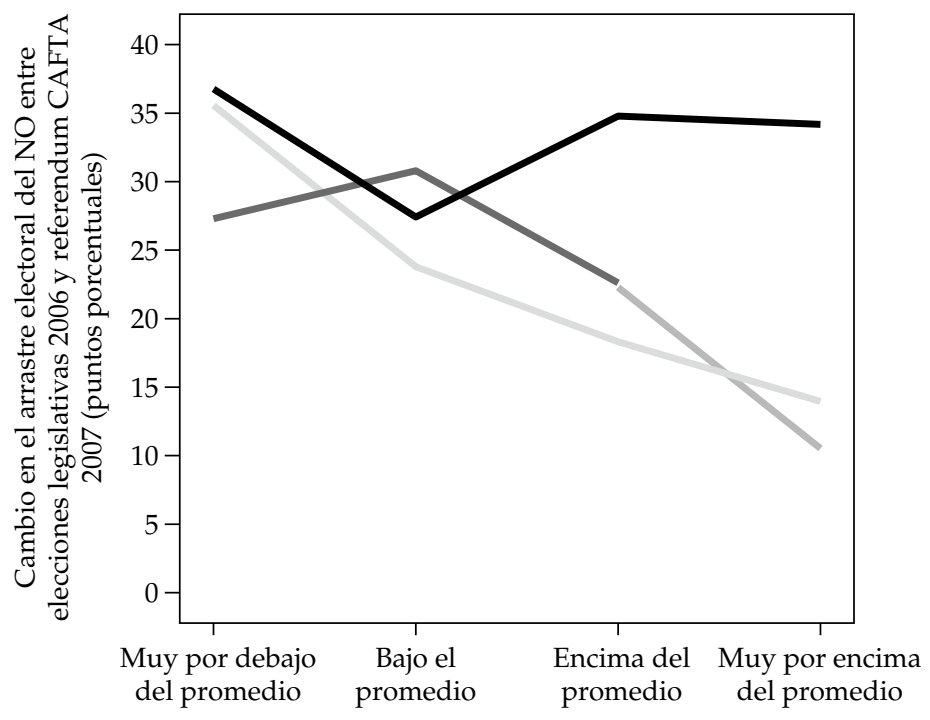

Nivel de desarrollo humano municipal

$$
\begin{aligned}
& \text { Magnitud de cambio abstención } \\
& \text { Muy por debajo del promedio } \quad \text { Bajo el promedio } \\
& \text { Encima del promedio } \quad \text { Muy por encima del promedio }
\end{aligned}
$$

Nota: El promedio de aumento abstención por municipio es el indicado en la nota al Gráfico 1. El promedio IDH municipal: 72,63, desviación estándar: 6,94. Las categorías para ambas variables están definidas a partir de las desviaciones estándares respecto al promedio: muy por debajo (o por encima) de este promedio $=1$ o más desviaciones estándares abajo (arriba).

Fuente: Elaboración propia con base en: (a) con base en el escrutinio definitivo del TSE sobre los resultados del referendum de octubre 2007 y de las elecciones nacionales de febrero de 2006. En: www.tse.go.cr (b) PNUD, para el IDH cantonal. 


\section{Reflexiones sobre el marco regulatorio del referendum}

La Ley 8492 que regula la celebración de referendums fue aprobada por la Asamblea Legislativa en abril de 2006. Fue aplicada por primera vez en la consulta sobre la ratificación del CAFTA, lo que significa una dura prueba para cualquier nueva legislación. La ley tiene defectos en áreas claves: las regulaciones relativas a las fuentes del financiamiento político, al gasto electoral y a la participación de funcionarios públicos en la deliberación del o los temas sometidos a consulta. En materia del financiamiento político se limita a establecer un tope (aproximadamente 8 mil dólares) por persona física. Sin embargo, este límite aplica también a las personas jurídicas, lo que en la práctica deja abierto un portillo para que se creen desbalances sustanciales en las campañas electorales.

En materia de gasto electoral, la ley es omisa. Dos provisiones razonables no fueron consideradas. No se establecieron topes de gasto electoral, que son fácilmente supervisables mediante el monitoreo de medios de comunicación y la obligación de las partes de abrir sus cuentas. Tampoco se incluyó ninguna referencia a un umbral mínimo de acceso a los medios de comunicación colectiva, con financiamiento público, de manera que los contendientes tuvieran garantía de que sus ideas pudieran ser conocidas por el público con cierto pie de igualdad. ${ }^{16}$ Cabe señalar que el acceso y la cobertura de los medios de comunicación fue uno de los asuntos que más fricciones creó durante el proceso electoral. El monitoreo de medios realizado por el TSE durante el período de julio a octubre arrojó la existencia de importantes desbalances en las principales empresas de medios, incluida la TV pública, generalmente a favor del SÍ, tanto en las secciones de información como en las de opinión (Cuadro 5).

Finalmente, la participación de los funcionarios públicos es otro importante vacío de la ley. La Ley 8492 contiene una norma que refiere al código electoral todo aquello que no quedó estipulado en ella. Sin embargo, en este tema -lo mismo que en materia del financiamiento político y el gasto electoral- la norma es inadecuada. ${ }^{17}$ Por ejemplo, en Costa Rica se exige plena neutralidad a los funcionarios públicos en relación con las elecciones donde se escoge a un nuevo gobierno. Sin embargo, en todas las democracias maduras los gobiernos y las oposiciones políticas y sociales están activamente ensarzados en los referendums, puesto que tratan sobre decisiones específicas de política pública. Aplicar las disposiciones del código electoral es contrario a la experiencia internacional, hecho que obliga a desarrollar un tipo de regulación distinta en esta materia. En síntesis, urgen las reformas legales en el marco regulatorio del referendum, como parte de una reforma política más amplia que, en términos generales, los partidos han estado renuentes a impulsar.

16 La noción de umbral mínimo o piso básico no implica que las partes tengan un acceso igualitario a los medios de comunicación colectiva. Significa que, en el peor de los casos, y si no consiguen financiamiento privado, tienen asegurada una cuota de presencia en los medios.

17 El código electoral tiene grave deficiencias en la regulación del financiamiento y gasto político (Casas, 2005). 


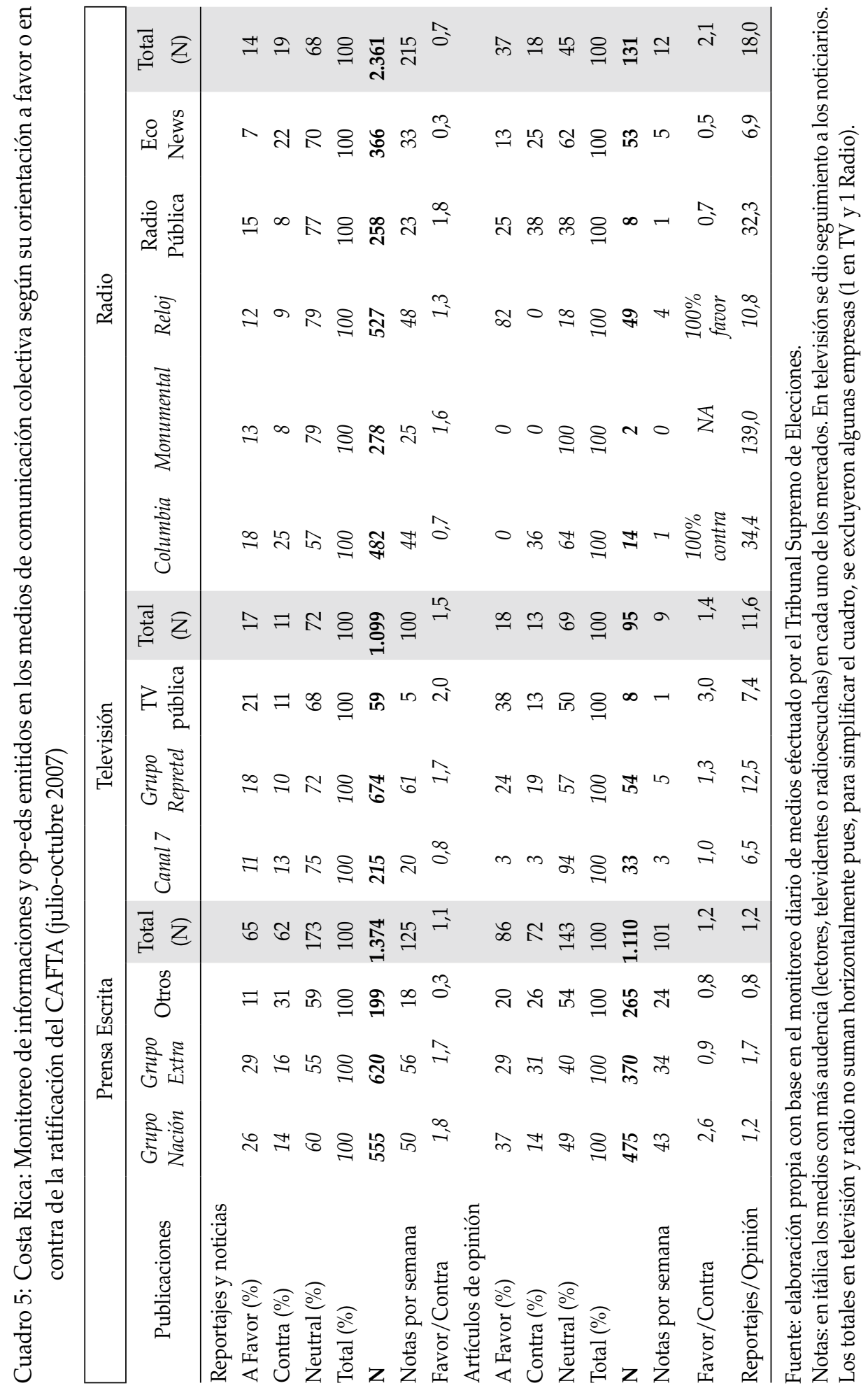




\section{PODER EJECUTIVO}

En el 2007 el Poder Ejecutivo obtuvo una importante victoria política, la ratificación del CAFTA. También, a diferencia de la administración de gobierno 2002-2006, logró mantener estables la composición del gabinete ministerial (sólo dos renuncias de ministros) y la dirección de las principales empresas públicas e instituciones descentralizadas (Cuadro 6).

En términos políticos, sin embargo, las dos renuncias en el gabinete ministerial fueron duras pérdidas. La salida del segundo vicepresidente y ministro de Planificación-persona del círculo interior del presidente-, como consecuencia del escándalo desatado por el memorandum Casas-Sánchez, implicó la pérdida de una de las piezas más importantes del gabinete. Significó, además, la pérdida de uno de los políticos jóvenes de mayor proyección dentro del PLN. Por otra parte, la renuncia de Alfredo Volio (ministro de la Producción), por razones no aclaradas ${ }^{18}$, implicó la paralización del impulso reformador del sector institucional relacionado con el fomento de la producción agropecuaria e industrial, una de las acciones que el gobierno había definido como prioritarias de su gestión. Las personas reemplazantes carecen del peso político que sus predecesores tenían dentro del gabinete.

Cuadro 6: Costa Rica: Cambios en la integración del Poder Ejecutivo, mayo 2006noviembre 2007

\begin{tabular}{|c|c|c|c|c|c|c|}
\hline \multirow[t]{2}{*}{ Cargo } & \multicolumn{3}{|c|}{ Mayo-diciembre 2006} & \multicolumn{3}{|c|}{ Enero-noviembre 2007} \\
\hline & Saliente & Entrante & Cargo & Saliente & Entrante & Cargo \\
\hline \multirow[t]{2}{*}{ Ministerios } & & & & Alfredo Volio & Marco Vargas & Producción \\
\hline & & & & Kevin Casas ${ }^{1}$ & Roberto Gallardo & Planificación \\
\hline $\begin{array}{l}\text { Proporción gabinete } \\
\text { de ministros }\end{array}$ & & & & 2 de 17 & & \\
\hline \multirow[t]{3}{*}{ Viceministerios } & Jose Lino Rodríguez & Silvia Víquez & Educación & & & \\
\hline & David Fuentes & José Luis Araya & Hacienda & & & \\
\hline & Esteban Arias & $\begin{array}{l}\text { Carlos Luis } \\
\text { Cascante }\end{array}$ & $\begin{array}{l}\text { Ciencia y } \\
\text { Tecnología }\end{array}$ & Jorge Woodbrige ${ }^{2}$ & José Eduardo Sibaja & Economía \\
\hline $\begin{array}{l}\text { Proporción gabinete } \\
\text { viceministros }\end{array}$ & 3 de 31 & & & 1 de 31 & & \\
\hline \multirow[t]{4}{*}{$\begin{array}{l}\text { Presidencias } \\
\text { ejecutivas }\end{array}$} & Jorge Gutiérrez & $\begin{array}{l}\text { Pedro Pablo } \\
\text { Quirós }\end{array}$ & ICE & Diego Víquez & José Antonio Lee & IMAS \\
\hline & José Oreamuno & Guido Vega & $\mathrm{CNP}$ & & & \\
\hline & Mauricio Cordero & Alberto Amador & IDA & & & \\
\hline & Paul Zúñiga & Urías Ugalde & Incoop & & & \\
\hline $\begin{array}{l}\text { Proporción gabinete } \\
\text { presidencias ejecut. }\end{array}$ & 4 de 20 & & & 1 de 20 & & \\
\hline
\end{tabular}

Fuente: Elaboración propia con base en La Gaceta del 8 mayo 2006 a 30 noviembre 2007.

${ }^{1}$ Renunció también a cargo de segundo vicepresidente de la República.

${ }^{2}$ Nombrado asesor presidencial con rango de ministro.

18 Pocos días antes de la renuncia de ministro Volio fueron públicas discrepancias con el Ministro de Comercio Exterior. 


\section{PODER LEGISLATIVO}

En el 2007 la conformación y dinámica de la Asamblea Legislativa no varió significativamente en relación con lo analizado en el 2006. Una vez más el Parlamento costarricense experimentó una trabazón que refleja las severas dificultades que padece desde hace años para adoptar decisiones en relación con reformas al sistema político e institucional y con políticas de promoción del desarrollo, pese a la condición favorable de mantener unida a una coalición mayoritaria más que mínima. ${ }^{19}$ A esta coalición se la denomina el G38. Aunque el G38 tiene una holgada mayoría parlamentaria (38 de 57 escaños), que le permitió efectuar cambios en el reglamento legislativo para agilizar el trámite de iniciativas de ley, la producción del Congreso fue magra tanto desde el punto de vista cuantitativo como cualitativo. En particular, no fue posible que en el 2007 la Asamblea Legislativa lograra procesar la ratificación del CAFTA, un objetivo estratégico de gobierno que de no haber sido por su trámite mediante el referendum éste no habría logrado.

En el período de enero a noviembre de 2007 la Asamblea Legislativa aprobó 65 leyes, la segunda cantidad más baja para un segundo año de gobierno durante el período 1994-2006 $6^{20}$ (Cuadro 7). De las 65 leyes, poco menos de dos terceras partes fueron "peccata minutiae": autorizaciones a otras entidades públicas para segregar bienes inmuebles, autorizaciones a gobiernos locales para el cobro de tasas y permisos, reconocimientos honoríficos a personajes notables y declaratorias de nuevos días de celebración (por ejemplo, la Ley 8626 que establece el "Día nacional para la prevención del embarazo en adolescentes"). La categoría de legislación ordinaria sustantiva (creación o reforma de nuevas entidades públicas y aprobación de presupuestos del gobierno central) representó apenas un 28\% de la producción legislativa y, salvo cuatro leyes, estuvo compuesta por iniciativas de carácter procedimental de poca monta y de reforma a legislación vigente..$^{21}$ Esta magra producción legislativa está asociada al cambio en el sistema de partidos (de bipartidismo a multipartidismo), que ha elevado la complejidad de las negociaciones y, desde 1994, a la sucesión de gobiernos divididos -el Ejecutivo no logra mayoría parlamentaria con los votos de su partido- en el contexto de un sistema electoral que desincentiva la formación de coaliciones. ${ }^{22}$

Sobre esta coalición de cinco partidos de centro-derecha, consúltese el artículo de Costa Rica en el anuario 2006 de esta misma revista (Vargas Cullell, 2007).

20 La cantidad de leyes aprobadas en los segundos años de gobierno en las últimas cuatro administraciones han sido las siguientes: 95 en 1995, 127 en 1999 y 62 en 2003.

21 Desde el punto de vista de los derechos de la población las cuatro leyes más destacadas son: la Ley 8589 de penalización de la violencia doméstica; la Ley 8590 de fortalecimiento de la lucha contra la explotación sexual de menores; la Ley 8591 para el fomento de la producción orgánica; la Ley 8624 de reforma a procedimientos relacionados con el cobro judicial.

22 Estos desincentivos no hacen sino destacar la novedad que significa, en el contexto costarricense, el que un gobierno haya logrado mantener estable una coalición más que mínima por casi 18 meses. Una condición externa -la pugna alrededor del CAFTA- es un factor clave para entender este hecho, además de la pericia política de la administración. 
Cuadro 7: Costa Rica: Tipo de legislación aprobada según órgano legislativo (1 enero a 30 noviembre 2007)

\begin{tabular}{lccrcc}
\hline \multicolumn{1}{c}{ Tipo de legislación ${ }^{1}$} & \multicolumn{5}{c}{ Órgano legislativo $^{2}$} \\
& Plenario & Miniplenarios & Referendum & Total & $\begin{array}{c}\text { \% según tipo } \\
\text { de legislación }\end{array}$ \\
\hline Autorizaciones locales & 35 & & 35 & 54 \\
Benemeritazgos & 6 & 2 & 1 & 7 & 11 \\
Convenios internacionales & 15 & 3 & & 18 & 28 \\
Legislación ordinaria sustantiva & 2 & 1 & & 3 & 5 \\
Otros & 58 & 6 & 1 & 65 & 100 \\
\hline Total & 89 & 9 & 2 & 100 & \\
\hline$\%$ según órgano & & & & & \\
\hline
\end{tabular}

Fuente: Elaboración propia con base en información de la Unidad de Análisis de la Gestión Parlamentaria, Departamento de Servicios Parlamentarios, Asamblea Legislativa.

${ }^{1}$ Tipo de legislación. Autorizaciones locales: autorizaciones para afectar o desafectar bienes inmuebles, patentes o impuestos municipales. Benemeritazgos: distinciones honoríficas a personas o instituciones. Convenios internacionales: aprobación de tratados, convenciones o convenios de carácter multilateral o bilateral. Legislación ordinaria sustantiva: legislación que crea nuevas entidades públicas, reforma existente y establece nuevas competencias legales a las instituciones públicas. Incluye la aprobación de presupuestos ordinarios y extraordinarios del gobierno central. Otros: aprobación de celebraciones (p. ej: día nacional para la prevención del embarazo en adolescentes).

${ }^{2}$ Órgano legislativo. Plenario: órgano compuesto por la totalidad de las y los diputados. Miniplenarios: órgano compuesto por un subconjunto de diputados. Su composición es decidida por el presidente legislativo. Existen 3 miniplenarios. Referendum: votación ciudadana para decidir sobre el CAFTA.

Durante los primeros meses del 2007, el gobierno se empeñó en lograr la ratificación parlamentaria del CAFTA, pues en el texto firmado Costa Rica tenía un plazo improrrogable de marzo del 2008 para ratificar (o rechazar) el tratado. Al desdeñar desde el 2006 el diálogo con el principal partido opositor, su táctica fue la de lograr esta ratificación mediante los votos del G38 cambiando, de ser necesario, las reglas parlamentarias para asegurar el trámite rápido del CAFTA. ${ }^{23}$ Esta táctica influyó decisivamente en el clima político y los acontecimientos sucedidos en la Asamblea Legislativa (hasta la fecha).

Con el apoyo del G38 se dictaminó el CAFTA en la Comisión de Asuntos Internacionales, un requisito indispensable para su posterior discusión en el plenario. Con este fin la presidencia del Parlamento estableció un plazo para la discusión, aunque no se hubiese concluido la deliberación de las mociones interpuestas por la oposición al tratado. Estas acciones escalaron las resistencias del PAC y partidos aliados, lo que desembocó en una compleja pugna procedimental que finalmente perdió el gobierno. En efecto, los partidos

23 Notablemente, la aplicación del "fast track" a un convenio internacional, opción anteriormente expresamente prohibida en el reglamento legislativo (reforma al artículo 204bis de dicho reglamento). 
opositores acudieron a la Sala Constitucional pues consideraron que se habían violentado sus derechos parlamentarios. Aunque la Sala reafirmó la mayor parte de lo actuado por la Presidencia del Congreso y el G38, encontró vicios de procedimiento que implicaron devolver el CAFTA a la comisión. El trámite significó un atraso de aproximadamente dos meses; cuando el tratado reingresó al plenario, la oposición presentó una gran cantidad de mociones, que debían ser discutidas en el plenario, y efectuó un manejo estratégico del quorum legislativo que ralentizó la deliberación y finalmente la estancó. Para cuando el TSE aceptó la aplicación del referendum a la ratificación del CAFTA, en abril del 2007, ya no había posibilidades de que en el Parlamento se sortearan los escollos procedimentales con el fin de lograr una votación sobre el tema en el 2007. Meses después, una vez ratificado el CAFTA, el gobierno enfrentó serias dificultades para lograr la aprobación de las leyes que forman parte de la agenda de implementación del tratado. Al momento de redactar este informe, sólo ha logrado la aprobación de 5 de las 14 leyes requeridas.

Por último, en relación con la composición personal y política del Parlamento es importante señalar que en el 2007 hubo pocos cambios. En el plano personal, se registraron dos renuncias de diputados, ambas del PAC. La primera fue la de la diputada González Morera, efectiva el 30 de junio, que se originó en conflicto de intereses. ${ }^{24}$ La segunda renuncia, la de la respetada diputada Bravo Pérez, fue efectiva el 30 de setiembre y se debió a razones personales. Cabe señalar que las renuncias de las parlamentarias del PAC contrastan con la negativa a dimitir por parte de dos legisladores del PLN, envueltos en escándalos, quienes fueron acuerpados por su dirigencia partidaria. ${ }^{25}$ Finalmente, a diferencia del período constitucional 2002-2006, que se caracterizó por las divisiones partidarias y el transfuguismo ${ }^{26}$ casi todas las fracciones parlamentarias de los principales partidos lograron mantener su unidad. La única baja la experimentó el Movimiento Libertario (ML), pues la jefa de su bancada durante la primera legislatura se apartó de su partido y se convirtió en diputada independiente. ${ }^{27}$ Aunque esta separación afectó al ML, no erosionó al G38 y más bien la fracción parlamentaria oficialista (PLN) ganó una aliada cercana.

\section{RELACIÓN ENTRE PODERES}

En el anuario del 2006 se señaló que las relaciones entre los poderes del Estado costarricense están signadas por un diseño estructural (presidencialista) que se caracteriza, en primer lugar, por un Poder Ejecutivo con atribuciones constitucionales y legales relativamente débiles para conducir el Estado y asegurar la disciplina en el Parlamento. En el balance de poderes, el Judicial tiene un peso inordinado como árbitro de decisiones públicas trascendentes, económica. Líderes del PAC intervinieron para que la inicialmente renuente diputada presentara su dimisión.

25 Se trata de los diputados Federico Tinoco, que fue denunciado por una funcionaria legislativa por acoso sexual, y Fernando Sánchez, coautor del memo Casas-Sánchez antes mencionado.

26 El 20\% de las y los diputados electos en el 2002 concluyeron su período en el 2006 en otros partidos o como diputados independientes.

27 Se trata de la diputada Evita Arguedas, a la que sus ex compañeros de partido acusaron ser muy complaciente con el gobierno del PLN. 
lo que ha trasladado cada vez más la lucha política al ámbito judicial. La clave de esta traslación es la existencia de un control de constitucionalidad amplio, fuerte, activo y de fácil acceso sobre la acción pública, que limita la iniciativa de los otros poderes y otorga amplios poderes de veto sobre cualquier política pública, sin costo alguno, a ciudadanos, organizaciones $u$ entidades si su apelación a la autoridad constitucional es aceptada. Adicionalmente, el aparato del Estado se caracteriza por múltiples y poderosos centros de poder institucional relativamente autónomos, dentro de los cuales el Ejecutivo es un actor más, uno ciertamente poderoso, pero no dominante. Existe un sector descentralizado de instituciones autónomas con independencia administrativa respecto al Poder Ejecutivo y al Poder Legislativo, que canaliza dos terceras partes del gasto público. Además de la revisión constitucional, el Estado costarricense cuenta con múltiples y robustos mecanismos de accountability horizontal y puntos de veto que controlan y delimitan constantemente las competencias y acciones del Ejecutivo y, en general, de la administración activa. Una poderosa Contraloría General, cuyas atribuciones y capacidades están entre las más fuertes de la región, vigila la legalidad del gasto público. Este diseño del sector público crea fuerte desincentivos a la cooperación entre actores políticos e institucionales pues el veto constitucional o legal a una política pública es fácil de accionar.

En el 2007 no se registra ninguna iniciativa del sistema de partidos para modificar el diseño estructural del Estado antes descrito. Frente al activismo constitucional registrado en la fase final del sistema bipartidista (Cuadro 8), cuando se aprobaron casi dos reformas constitucionales por año, el 2007 continuó la tendencia conservadora observada en el último lustro de efectuar pocas innovaciones constitucionales. Cabe subrayar que en este período el sistema político se ha caracterizado por un multipartidismo inestable, lo que ha elevado la dificultad de formar mayorías para cualquier reforma. Por otra parte, ninguna de las aproximadamente 14 mil resoluciones de la Sala Constitucional durante el 2007 provocó cambios en las reglas básicas del sistema político e institucional costarricense. ${ }^{28}$

Aunque el 2007 no fue relevante en cuanto a innovaciones en la arquitectura institucional, sí lo fue en otro sentido: por una parte, se reafirmó el papel de árbitro de los conflictos políticos que la Sala Constitucional ha venido desempeñando en los últimos años y, por otra, se reafirmó la función e independencia del TSE como suprema autoridad electoral y "cuarto" poder de la república. ${ }^{29}$ En relación con la función arbitral de la Sala Constitucional los hechos más destacados fueron sus resoluciones sobre el procedimiento de aprobación parlamentaria del CAFTA y su pronunciamiento acerca de la constitucionalidad de los contenidos del tratado, en respuesta a las consultas de parte de la Defensoría de los Habitantes y de congresistas opositores al tratado (Resolución 2007-09469 del 3 julio 2007). Estas sentencias tuvieron un fuerte impacto político sobre los términos del conflicto político del CAFTA.

29 En el artículo 9 de la Constitución Política se reconoce un rango de poder constitucional al TSE. 
Cuadro 8: Costa Rica: sistema de partidos y activismo constitucional (1960-2007)

\begin{tabular}{|c|c|c|c|c|}
\hline Sistema de partidos ${ }^{1}$ & Período $^{2}$ & $\begin{array}{c}\text { Reformas } \\
\text { constitucionales } \\
\text { aprobadas }\end{array}$ & $\begin{array}{c}\text { Reformas } \\
\text { constitucionales/año }\end{array}$ & NEPL $^{3}$ \\
\hline $\begin{array}{l}\text { Sistema bipolar } \\
\text { hegemónico }\end{array}$ & 1960 a 1982 & 10 & 0,5 & $\begin{array}{l}\text { Inestable: varía entre } \\
2,0(1953) \text { y 3,5 (1974) }\end{array}$ \\
\hline $\begin{array}{l}\text { Sistema bipartidista } \\
\text { estable }\end{array}$ & 1982 a 1998 & 11 & 0,7 & $\begin{array}{l}\text { Estable: varía entre } \\
2,2-2,5\end{array}$ \\
\hline $\begin{array}{l}\text { Sistema bipartidista } \\
\text { en transición }\end{array}$ & 1998 a 2002 & 7 & 1,8 & $\begin{array}{l}\text { Inestable: pasa de } 2,5 \\
\text { a } 3,7\end{array}$ \\
\hline $\begin{array}{l}\text { Multipartidismo } \\
\text { inestable }\end{array}$ & 2002 a hoy & 3 & 0,5 & $\begin{array}{c}\text { Estable: pasa de } 3,7 \\
\text { a } 3,4\end{array}$ \\
\hline Total & & 31 & 0,6 & \\
\hline
\end{tabular}

Fuente: Elaboración propia con base en información de la Unidad de Análisis de la Gestión Parlamentaria, Departamento de Servicios Parlamentarios, Asamblea Legislativa. Datos sobre NEPL son del XII Informe Estado de la Nación (2006).

${ }^{1}$ Sistema de partidos. Sistema bipolar: un mismo partido (PLN) obtiene la mayoría parlamentaria en todas las elecciones legislativas y triunfa en 3 de las 5 elecciones parlamentarias; los partidos opositores forman alianzas electorales para enfrentar al PLN, coaliciones que se caracterizan por su inestabilidad y rotación de partidos miembros. Sistema bipartidista estable: número efectivo de partidos cercano a 2 en las elecciones presidenciales (PLN-PUSC), menor a 2,5 en las elecciones legislativas y con una alta participación electoral (cercana al 80\%). Sistema bipartidista inestable: número efectivo de partidos cercano a 2 en las elecciones presidenciales (PLN-PUSC), mayor a 2,6 en las elecciones legislativas y con menor participación electoral (circa 70\%). Sistema multipartidista inestable: número efectivo de partidos mayor a 3 en las elecciones presidenciales y legislativas, volatilidad superior a 30\% y con menor participación electoral (circa 65\% de ciudadanía).

2 Período. En Costa Rica las elecciones nacionales se celebran el primer domingo de febrero cada cuatro año. En consecuencia, los períodos se cuentan hasta la elección nacional donde se marcó el cambio. 1982 indica "febrero 1982". Por lo general, el Congreso decreta receso a más tardar en diciembre del año anterior, por lo que para efectos de clasificación del período al que pertenece una reforma se toma en cuenta hasta esta fecha. Así, el período 1960 a 1982 va de 01/01/1960 a 31/12/1981. Los períodos restantes deben interpretarse de manera análoga.

${ }^{3}$ NEPL: Número de partidos efectivos en la Asamblea Legislativa.

El TSE tuvo un protagonismo político que dista sustancialmente de la inercia y autolimitación que caracterizó su accionar durante la década anterior. ${ }^{30}$ En los últimos cinco años, período durante el cual se registró un cambio en la composición de este órgano, ${ }^{31}$ el tribunal ha debido organizar 6 procesos electorales (incluido el referendum), en contraste con la experiencia del período 1952-1998, cuando su actividad se limitaba a organizar un proceso

30 En estos años, la Sala Constitucional hubo de recordarle al Tribunal que, de acuerdo con la Constitución Política, es la máxima autoridad electoral, en el ámbito jurisdiccional y administrativo, luego de que el TSE se negara a resolver varios casos (Votos 2150-92; 3194-92 y 3813-93).

31 Una nueva generación de magistrados, todos entre 40 y 50 años, preside en la actualidad este organismo. 
electoral cada cuatro años. ${ }^{32}$ Presidió además sobre dos elecciones particularmente reñidas (los comicios presidenciales de febrero de 2006 y el referendum de octubre 2007), donde hubo alegaciones (infundadas) de irregularidades. ${ }^{33} \mathrm{Al}$ aceptar la iniciativa ciudadana para convocar a un referendum sobre el CAFTA el Tribunal cambió, de súbito, el ámbito de la discusión sobre el tema: a partir de entonces ésta pasó de ser una lucha centrada en el Parlamento a una competencia por el voto de los electores. Finalmente, su decisión de convocar al referendum, una vez que la Asamblea Legislativa aprobó la propuesta del Ejecutivo, puso fecha cierta a la ratificación del tratado y, con ello, término político a un conflicto cada vez más complejo y polarizado.

\section{FUNCIONAMIENTO Y CALIDAD DE LA DEMOCRACIA}

El año 2007 fue un año político importante, pues finalmente logró resolverse la cuestión de la ratificación de CAFTA, un tema que desde hace casi cuatro años venía paralizando y polarizando las fuerzas políticas en Costa Rica. Esta decisión vino asociada a un alto costo político para el gobierno. Pese a tener un año de buenos resultados económicos y sociales, experimentó sensibles bajas en su aparato de conducción, una reducción de su base política y un relegamiento de la agenda de reforma institucional planteada en el Plan Nacional de Desarrollo debido a la concentración de esfuerzos en lograr la ratificación del tratado. Este desgaste lo coloca en una situación compleja de cara al 2008, pues aún tiene pendiente la aprobación de la mayoría de las leyes que conforman la agenda de implementación del CAFTA sin que, por otra parte, haya podido impulsar la agenda de reformas fiscales e institucionales previstas en el Plan Nacional.

Debido a la corta duración de los mandatos presidenciales en Costa Rica, la administración de gobierno del presidente Arias habrá consumido su primera y potencialmente más fructífera etapa en lograr la puesta en vigencia del CAFTA, una herencia del gobierno anterior. La segunda mitad de su mandato, que coincidirá con las actividades preelectorales, será un contexto político poco propicio para intentos reformistas. En este período, los poderes efectivos de la presidencia para mantener la disciplina en su propio partido se reducen significativamente (Carey, 1997); por otra, los partidos aliados en el G38 deberán tomar distancia del gobierno para preservar sus identidades políticas -en principio, opositoras al PLN; y, finalmente, el PAC deberá endurecer sus posiciones para presentarse como el "verdadero" opositor al PLN y los partidos de centro-derecha. Por su parte, luego de su derrota en el referendum, la oposición centrada en el PAC enfrenta la difícil tarea de migrar de una posición refractaria a intentos reformistas del statu quo, a delinear una propuesta de gobierno de cara al período 2010-2014. En particular, deberá posicionarse ante el electorado

32 En el año 2002 la elección presidencial constó de dos rondas, pues ningún candidato obtuvo el $40 \%$ de los votos válidos en los comicios de febrero de ese año; además, por primera vez se celebraron las elecciones para elegir alcaldes municipales en diciembre de ese año. En el 2006, el TSE organizó las elecciones nacionales (presidenciales, legislativas y municipales) en febrero y en diciembre organizó las elecciones de los alcaldes. En octubre 2007 se celebró el referendum sobre el CAFTA, que debió preparar con apenas tres meses de antelación.

33 En relación con la limpieza de las elecciones de febrero 2006 cfr: Alfaro, 2007 
como una fuerza con vocación y capacidad de gobierno, cosa que no ha logrado hasta el momento. En este contexto, el resultado más probable será la postergación por varios años de las reformas políticas e institucionales orientadas a generar una mayor calidad de la representación política y mayor eficacia en la gestión pública.

\section{REFERENCIAS}

Alfaro, Ronald. 2007. De elecciones y cuestionamientos a los resultados: el caso de los comicios costarricenses del 2006. San José: ponencia realizada para el Decimotercer Informe Estado de la Nación. [En línea] $<$ www.estadonacion.or.cr $>$.

Carey, John. 1997. "Strong Candidates for a Limited Office: Presidentialism and Political Parties in Costa Rica". In Mainwaring, Scott y Mathew Shugart (Eds.), Presidentialism and Democracy in Latin America. New York: Cambridge University Press, 199-224.

Casas, Kevin. 2005. Paying for Democracy. Essex: European Consortium for Political Research.

CEPAL. 2007. Balance preliminar de las economías de América Latina y el Caribe 2007. Santiago: CEPAL.

CID-Gallup. 2007. Encuesta de Opinión Pública Costa Rica. San José: número 115, 19-27, octubre, 2007.

Consulta Mitofski. 2007a. Aprobación de mandatarios. América y el Mundo. Octubre 2007. [En línea] <www.consulta.com.mx/omteropres/99_pdfs/14entorno_i_pdf/20080101/INT/EvaMan.pdf>. [Consulta 3-3-2008]

. 2007b. Aprobación de mandatarios. América y el Mundo. Mayo 2007. [En línea] <www.amai. org/datos_files_Zta4gb.pdf> [Consulta 3-3-2008]

2007c. Aprobación de mandatarios. América y el Mundo. Enero 2007. [En línea] <www. fundadesc.org/documentos/67evaluacion\%20mandatariosMitofsky.pdf $>$. [Consulta 3-3-2008]

Franklin, Mark; Van der Eljk Cesc; Marsh, Michael. 2005. “Referendum Outcomes and Trust in Government: Public Support for Europe in the Wake of Maastrich". West European Politics, Vol 18. [En línea] $<$ http:/ / www2.trincoll.edu/ mfrankli/ReferendumTrust.pdf $>$ [Consulta 3-3-2008]

Kowalska, Adrianna y Kubiak, Maciej. 2005 "Ratification procedures re: the EU constitutional treaty - models and consequences". Warsaw: Erasmus Society Seminar on European Constitutionalism, April 25-27

Leduc, Lawrence. 2002. "Opinion change and voting behaviour in referendums". European Journal of Political Research 41(6): 711-732

Maravall, José María. 2003. El control de los políticos. Madrid: Taurus.

Mendelsohn, Mathew y Parkin, Andrew (ed). 2001. Referendum Democracy: Citizens, Elites and Deliberation in Referendum Campaigns. London: Palgrave

Ministerio de Planificación y Política Económica (MIDEPLAN). 2007. Plan Nacional de Desarrollo 2007-2001. San José: Imprenta Nacional.

Programa Estado de la Nación. 2007. Decimotercer Informe Estado de la Nación. San José: Imprenta Lil. . 2006. Decimosegundo Informe Estado de la Nación. San José: Imprenta Lil.

Sauma, Pablo. 2007. Consideraciones sobre la pobreza en Costa Rica. San José: presentación en la Contraloría General de la República, 30 noviembre 2007.

Semanario Universidad. 2007. "El que paga la orquesta..." San José: edición 556 Semana 11 a 17 de ocubre, página 7 .

Tribunal Supremo de Elecciones (TSE). 2007. Resultados definitivos, Referendum 2007. [En línea] <http:/ / www.tse.go.cr/referendum.htm> [Consulta: 28-11- 2007].

2006a. Resultados Definitivos para la Elección de Presidente y Vicepresidentes de la República, Elecciones 5 de febrero del 2006. En: http:/ / www.tse.go.cr/actas_escru.htm. [Consulta: 06-3- 2007].

2006b. Resultados Definitivos para la Elección de Diputados a la Asamblea Legislativa, Elecciones 5 de febrero 2006. [En línea] <http://www.tse.go.cr/actas_escru_diputados.htm>. [Consulta: 06-3- 2007]. 
Ulibarri, Eduardo. 2008. "El año que doblamos la esquina". En: La Nación. San José: 6 de enero de 2008. [En línea] <www.nacion.com>

UNIMER, RI. 2005. Encuesta para el diario La Nación. San José: Noviembre 2005. En línea] <www.nacion. com>

2006. Encuesta para el diario La Nación. San José: Enero 2006. En línea] <www.nacion.com>

Jorge Vargas Cullell. Costarricense. Director Adjunto del Programa Estado de la Nación. Ph.D en Ciencias políticas por la Universidad de Notre Dame (EE.UU) y Licenciado en sociología por la Universidad de Costa Rica. Investigador, ha sido consultor para organismos internacionales, entidades locales y funcionario público. Autor de diversos libros y artículos para revistas especializadas. Entre los más recientes: "La cultura política de la democracia en Costa Rica (2006)" y "Costa Rica: democracia estable ¿alcanza?" ambos en coautoría. Presidente de la Fundación Promotora de Vivienda, dedicada a la solución de problemas habitacionales de hogares de bajo ingreso. Columnista semanal en el principal diario del país.

(Email jorgevargas@estadonacion.or.cr). 
